\title{
TECHNOLOGICAL PECULIARITIES OF LASER, MICROPLASMA AND HYBRID LASER-MICROPLASMA WELDING OF ALUMINIUM ALLOYS
}

\author{
V.D. SHELYAGIN ${ }^{1}$, A.M. ORISHICH ${ }^{2}$, V.Yu. KHASKIN ${ }^{1}$, A.G. MALIKOV ${ }^{2}$ and A.A. CHAJKA ${ }^{1}$ \\ ${ }^{1}$ E.O. Paton Electric Welding Institute, NASU \\ 11 Bozhenko Str., 03680, Kiev, Ukraine. E-mail: office@paton.kiev.ua \\ ${ }^{2}$ S.A. Khristianovich Institute of Theoretical and Applied Mechanics, Siberian Branch of RAS \\ 4 /1 Institutskaya Str., 630090, Novosibirsk, Russia. E-mail:admin@itam.nse.ru
}

\begin{abstract}
Actuality of application of laser, microplasma and hybrid laser-microplasma (HLMP) methods of aluminium alloys welding is shown. Technological schemes of laser and laser-microplasma welding are selected. Appropriate experiments have been carried out for study of technological peculiarities of three selected methods for producing butt and edge sheet joints. It was found that there are the following main drawbacks in microplasma welding: in case of complete penetration a weld sagging is observed, at welding currents of more than 30 A the tendency to undercut formation takes plase, with increase in speed for more than $40 \mathrm{~m} / \mathrm{h}$ the stability of process is decreased. It is characteristic of HLMP welding: stability of the process at high (above $60 \mathrm{~m} / \mathrm{h}$ ) speeds of welding, decrease (by 1.5-2 times as compared with microplasma welding) in width of welds, significant decrease (up to full removal) in residual deformations, absence of spattering. It was found that typical defects of laser and laser-microplasma welding of are the sagging of welds, made without backing, formation of undercuts and inner pores of $0.1-0.2 \mathrm{~mm}$ diameter. The following main ways of elimination of these defects can be taken into consideration: feeding of filler materials (for example, in the form of wire); use of steel backings (including those with grooves for lower bead formation); welding along raised edge (with edge welds); application of welding modes with modulation of sources power; overlap welding (requires careful preparation of surfaces). Optimum values of energy input in $\mathrm{CO}_{2}$-laser welding are 36-70 $\mathrm{J} / \mathrm{mm}$ by the criteria of quality of joints formation, absence of pores and cracks. Reduction of energy input leads to disappearance of key hole and lack of penetration of metal, while increase in energy input - to hot crack formation. Typical macro- and microstructure of metal of welds and HAZ made by microplasma, hybrid and laser welding are given. 7 Ref., 11 Figures.
\end{abstract}

$\boldsymbol{K} \boldsymbol{e} \boldsymbol{y} \boldsymbol{w} \boldsymbol{o r d s}:$ welding, aluminium alloys, laser emis sion, microplasma, hybrid laser-microplasma welding, types of joints, experiments, modes, structures

Aluminium alloys are widely used in nowadays industry for manufacture of light structures. The main peculiarity of their welding is the need in removal of oxide film $\mathrm{Al}_{2} \mathrm{O}_{3}$, formed on the surface during interaction with air oxygen. Commonly, the surfaces of these alloys for their welding are prepared by a mechanical method. Microplasma welding with variable-polarity pulses gives an opportunity of a cathode cleaning of surfaces being welded [1]. Combination of processes of laser and microplasma welding allows not only providing the cleaning of surfaces, but also contributing to the formation of a hybrid laser-plasma discharge, which gives a possibility to significantly increase the welding efficiency, and also quality of welded joints [2]. However, it does not mean that it diminishes the actuality of the laser welding. According to data of some researchers [3], a proper selection of laser welding modes allows producing quality joints at minimum overheating of the base metal.

In literature [3, 4], the results of testing different technological schemes of laser and lasermicroplasma welding are described. Usually, the laser welding of aluminium alloys is performed using the quality gas shielding of upper and lower sides of the weld (Figure 1). Scheme, shown in Figure 2, can be considered as one of the most promising ones for joining the sheet aluminium alloys [4]. In investigations, carried out using this scheme, the peculiarities of formation of joints in the range of $40-200 \mathrm{~J} / \mathrm{mm}$ energy inputs were studied. However, the welding of thinwalled products in the range of $10-30 \mathrm{~J} / \mathrm{mm}$ also represents an interest. One of the aspects of the present work is devoted to the investigations for producing quality joints in this range.

The second important moment is the defining the optimum energy inputs of laser welding of similar products. In this case, as a criterion of optimization it is rational to study the quality of 


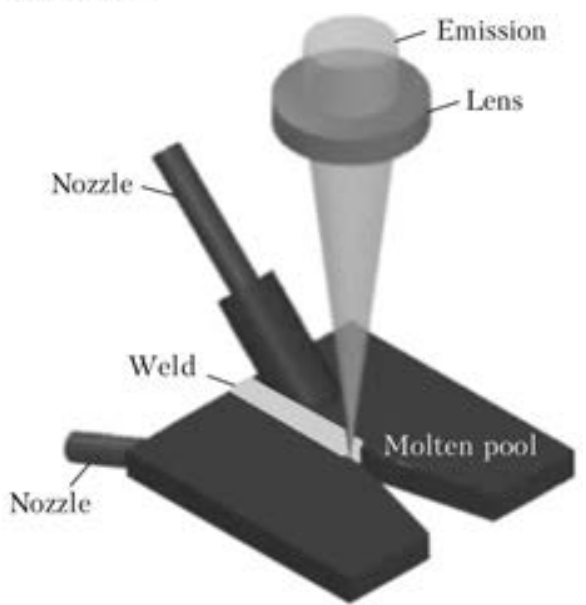

Figure 1. Technological scheme of laser welding of aluminium alloys

formation of joints, absence of defects in the form of pores and cracks, as well as minimization of HAZ.

Therefore, the aim of work was to study the technological peculiarities of laser, microplasma and hybrid laser-microplasma (HLMP) welding of thin-walled products of aluminium alloys for producing quality permanent structures used in aircraft and rocket construction. Such formation of welds was selected as the criteria of quality of welded joints, at which undercuts, lack of penetration, inner pores, blowholes were absent and also the finest-dispersed structures of metal of welds and HAZ were formed.

Investigation of welding of sheet aluminium alloys by $\mathrm{CO}_{2}$-laser at wave length $\lambda=10.6 \mu \mathrm{m}$ was carried out at the S.A. Khristianovich Institute of Theoretical and Applied Mechanics ( $\mathrm{Si}-$ berian Branch of RAS). To produce welded joints, the automated laser technological complex (ALTC) «Sibir 1», designed at S.A. Khristianovich ITAM, was used, which included the continuous $\mathrm{CO}_{2}$-laser of up to $8 \mathrm{~kW}$ at beam quality parameter 0.7 [5], technological table of gantry type and computer system of ALTC control (Figure 3). Laser emission was focused to

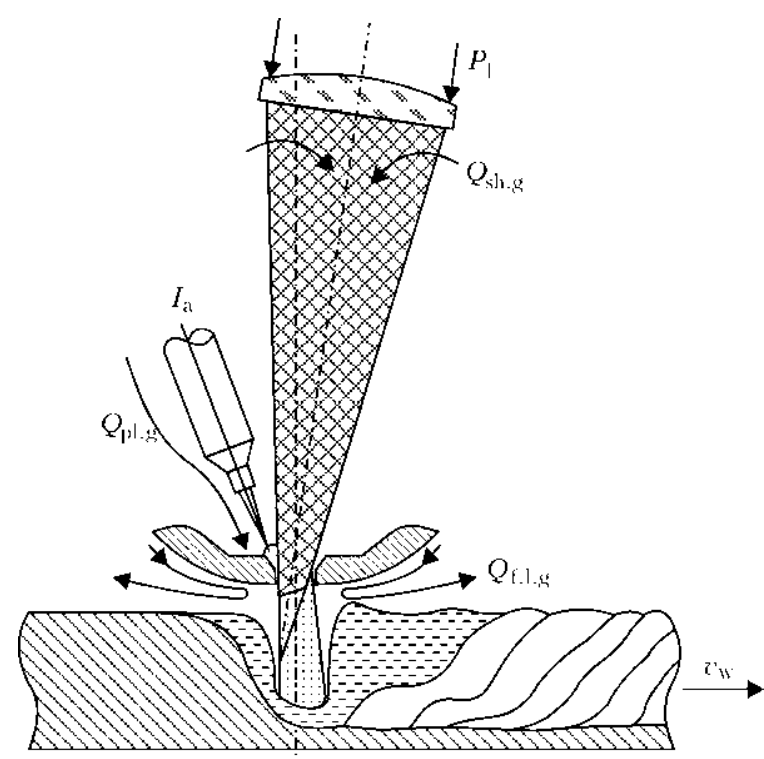

Figure 2. Scheme of hybrid welding process realized by using integrated direct-action plasmatron: $P_{1}-$ laser power, $\mathrm{kW} ; I_{\mathrm{a}}-$ welding current, A; $Q_{\mathrm{f} . l . g}-$ consumption of gas shielding the focusing lens, $1 / \mathrm{min}$; $Q_{\mathrm{pl} . \mathrm{g}}-$ consumption of plasma gas, $1 / \min ; Q_{\text {sh.g }}-$ consumption of shielding gas, $\mathrm{l} / \mathrm{min} ; v_{\mathrm{w}}-$ welding speed, $\mathrm{m} / \mathrm{h}$

metal surface by means of ZnSe-lens at $254 \mathrm{~mm}$ focal distance.

According to scheme of Figure 1, $a$, jet of helium gas was supplied co-axially with a laser beam. To shield the weld being formed, a shielding nozzle was used, from which the same gas was supplied. Weld root was shielded by argon. During experiments a welding head was arranged above a fixed workpiece. Optimum power parameters of laser welding of alloy AMg5 were determined during investigations.

At the E.O. Paton Electric Welding Institute a complex of laser-microplasma welding with a hybrid plasmatron, shown in Figure 4, was manufactured, which allows realizing a selected scheme of welding (see Figure 2). The peculiar features of this plasmatron refer to the arrangement of axes of tungsten electrode and focused emission at minimum angles to vertical. To focus
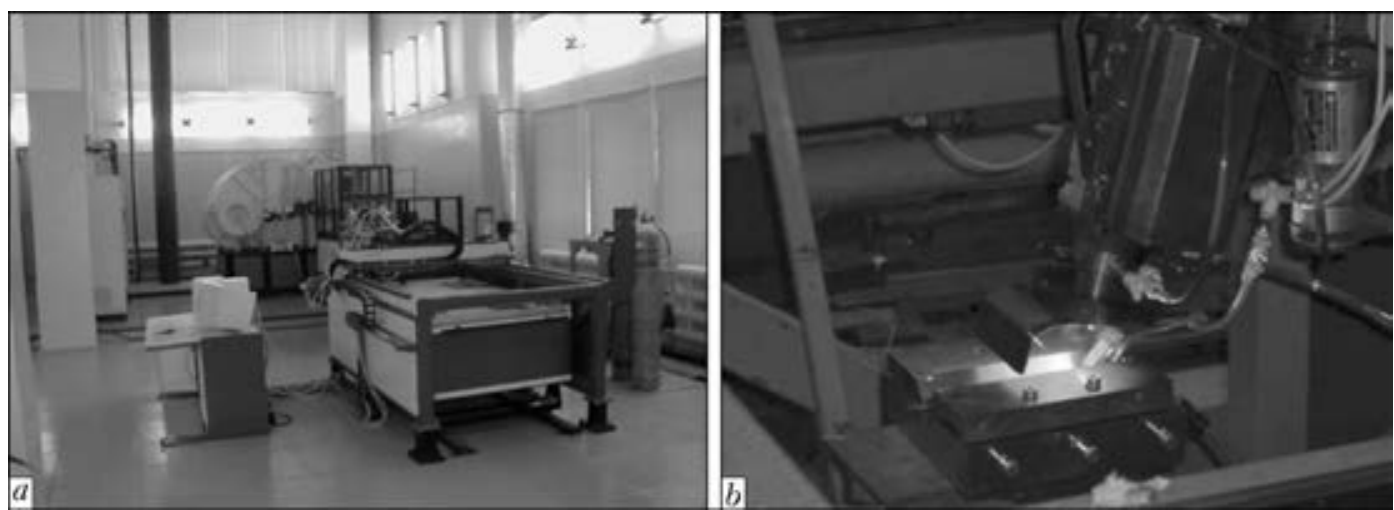

Figure 3. Appearance of ALTC «Sibir 1» $(a)$ and laboratory stand $(b)$ for laser welding 


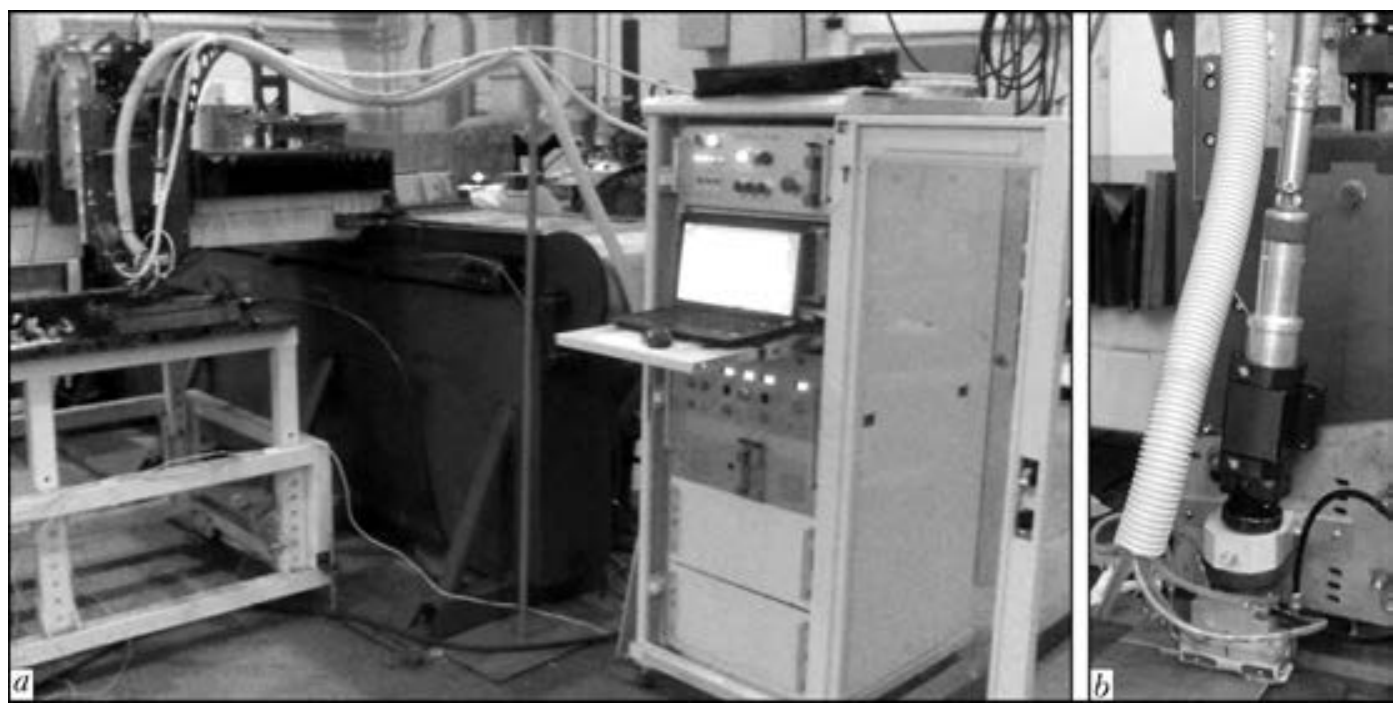

Figure 4. Appearance of complex of laser-microplasma welding ( $a$ ) and hybrid plasmatron $(b)$

the emission of fiber laser of YLR-400-AC model (IPG, Germany) $(\lambda=1.07 \mu \mathrm{m}$, power of up to $400 \mathrm{~W}$ ), the lens with $200 \mathrm{~mm}$ focal distance, shielded from entry of welding aerosols by a gas (argon) and protective glass, was used. Consumption of argon, shielding the lens, was $Q_{\text {f.l.g }}=$ $=3-6 \mathrm{l} / \mathrm{min}$. Arc plasma was generated using a tungsten electrode of $1.6 \mathrm{~mm}$ diameter, copper plasma-forming nozzle with $1.5 \mathrm{~mm}$ diameter hole. Argon was used as plasma and shielding gas with consumptions $Q_{\text {pl.g }}=0.1-0.31 / \mathrm{min}$, $Q_{\text {sh.g }}=6-9 \mathrm{l} / \mathrm{min}$. Welding current of straight polarity, used in experiments, did not exceed $40 \mathrm{~A}$ at arc voltage of up to $22 \mathrm{~V}$.

Hybrid plasmatron was supplied from power source of MPU-50 type, designed for continuous and pulsed welding currents of up to $50 \mathrm{~A}$. Laser emission was supplied to plasmatron by means of a collimator. Plasmatron was fastened to the three-coordinate manipulator carrier, on the working table of which a welding clamping frame was arranged for fixation of specimens.

Alloys $\operatorname{AMg} 2(\delta=1$ and $2.5 \mathrm{~mm}), \operatorname{AMg} 4(\delta=$ $=1 \mathrm{~mm}), \operatorname{AMg} 5(\delta=1.5 \mathrm{~mm})$ and $\operatorname{AMg} 6(\delta=$ $=1.4 \mathrm{~mm}$ ) were used as a material for specimens to be welded. Size of specimens was $(100-300) \times$ $\times(10-50) \times \delta \mathrm{mm}$. Welding was performed without backing. Laser welding of butt welds was performed both by $\mathrm{CO}_{2}$-laser and also by fiber laser. In case of $\mathrm{CO}_{2}$-laser the emission power was enough to provide a stable penetration. In welding with the fiber laser the power of continuous emission of $400 \mathrm{~W}$ was not enough for producing the penetration of depth of more than $0.1-0.3 \mathrm{~mm}$ because of a high reflection.

In experiments on microplasma and hybrid welding of butt and edge joints the current of straight polarity $I_{\text {str }}$ was set within $10-40 \mathrm{~A}$, while that of reverse polarity $I_{\text {rev }}$ was $6-15 \mathrm{~A}$, duration of pulses of straight polarity $\tau_{\text {str }}=20$ and $30 \mathrm{~ms}$, while that of reverse polarity $\tau_{\text {rev }}=$ $=10 \mathrm{~ms}$.

Experiments on microplasma welding with variable-polarity pulses allowed revealing the following main drawbacks (Figure 5): in case of complete penetration the weld sagging takes place; at higher currents of straight polarity (above $30 \mathrm{~A}$ ) the tendency to undercut formation is observed; at increase of speed $\left(v_{\mathrm{w}} \geq 40 \mathrm{~m} / \mathrm{h}\right)$ the process stability is deteriorated.

Experiments on HLMP welding showed the main advantages, namely stability of the process at higher (above $60 \mathrm{~m} / \mathrm{h}$ ) speeds of welding was increased; width of welds was 1.5-2.0 times decreased; residual deformations were significantly decreased; spattering was absent. Such peculiarity of hybrid welding was found as tendency to formation of undercuts in butt joints at currents of straight polarity of above 30 A (Figure 6).

Investigation of ways of elimination of typical defects of laser-microplasma welding of aluminium alloys showed that the following ones can be considered as main: feeding of filler ma-

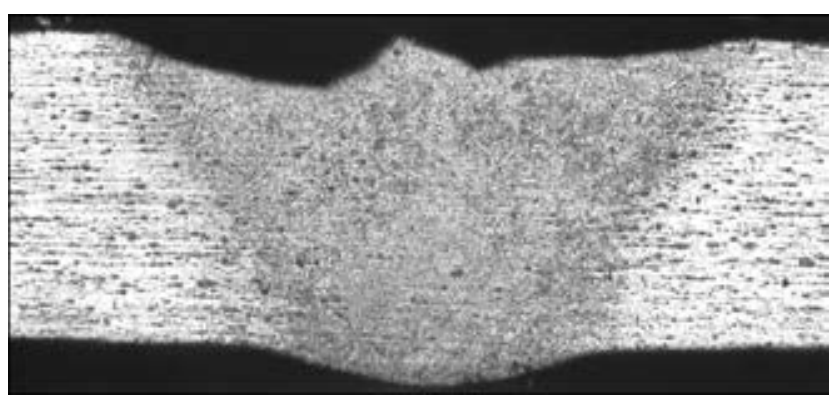

Figure 5. Macrostructure $(\times 25)$ of cross section of butt plasma-welded joint of alloy $\operatorname{AMg} 6(\delta=1.4 \mathrm{~mm})$ at $v_{\mathrm{w}}=$ $=30 \mathrm{~m} / \mathrm{h}$ 


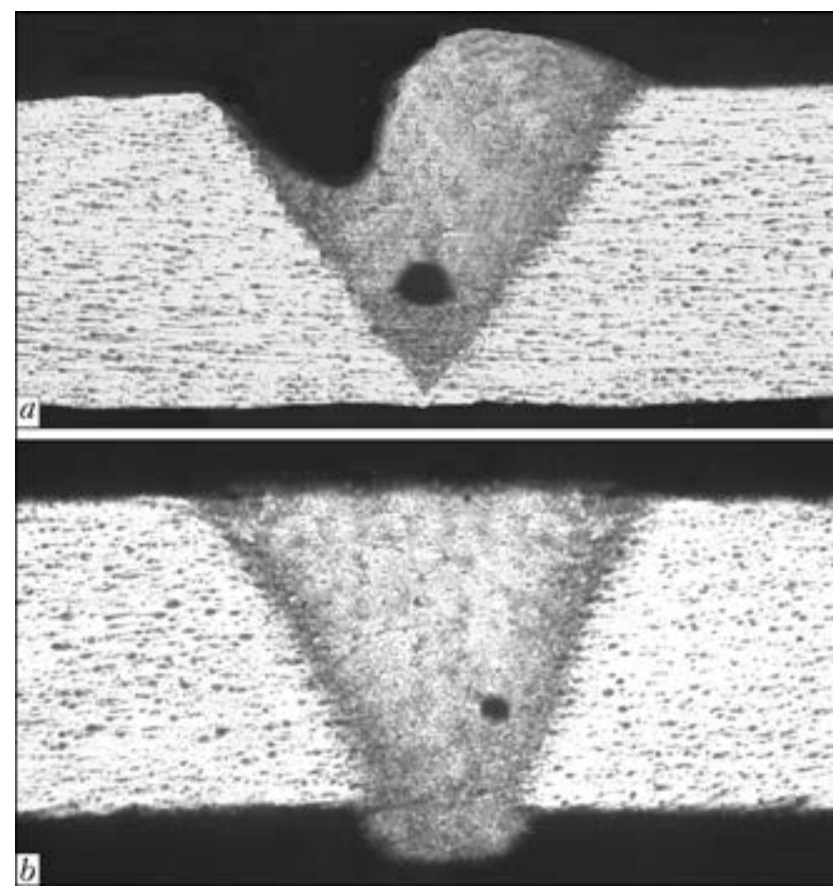

Figure 6. Macrostructure $(\times 25)$ of cross section of penetration $(a)$ and butt joint $(b)$ made by hybrid method on alloy $\operatorname{AMg} 6(\delta=1.4 \mathrm{~mm})$ at $v_{\mathrm{W}}=150 \mathrm{~m} / \mathrm{h}$

terial; welding along raised edges or by edge welds (Figure 7); overlap welding.

To carry out the metallographic examinations, the templates were cut out from welded specimens in weld cross section, which then were clamped into aluminium clamping frames, grinded and polished (electric polishing was used). The microstructure was revealed by etching in solution of $10 \mathrm{~cm}^{3}$ of hydrofluoric acid, $15 \mathrm{~cm}^{3}$ of hydrochloric acid and $30 \mathrm{~cm}^{3}$ of water. The obtained samples were studied in optic microscope «Neophot-30» at magnifications from 25 up to 500 .

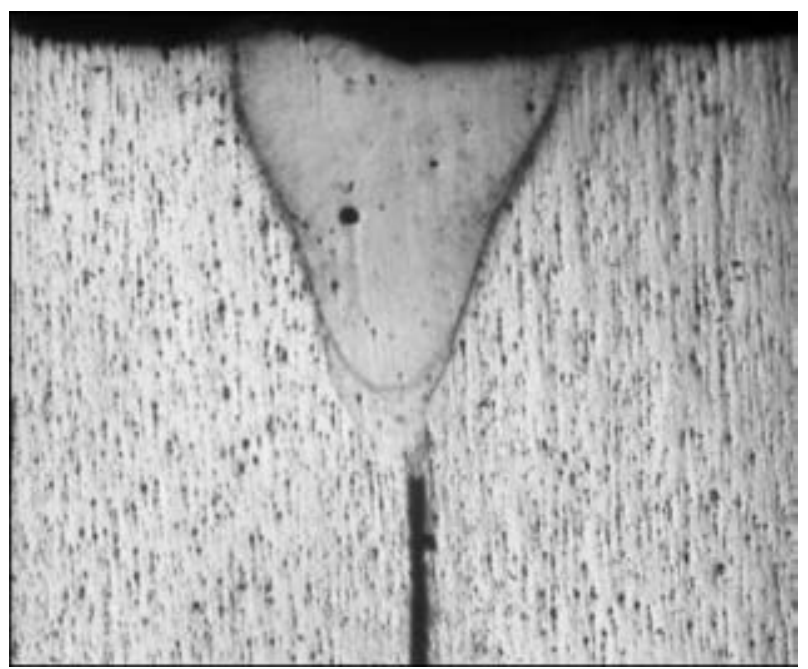

Figure 7. Macrostructure $(\times 25)$ of cross section of quality edge joint of alloy $\mathrm{AMg} 6(\delta=1.4 \mathrm{~mm})$ made by hybrid method at $v_{\mathrm{w}}=168 \mathrm{~m} / \mathrm{h}$
Firstly, the panoramic types of AMg6 alloy welds $(\delta=1.4 \mathrm{~mm})$ were studied (Figures $5-7)$. Figure 5 shows macrostructure of cross section of plasma-welded joint at the mode: $I_{\text {str }}=30 \mathrm{~A}$, $I_{\text {rev }}=10 \mathrm{~A}, \tau_{\text {str }}=20 \mathrm{~ms}, \tau_{\text {rev }}=10 \mathrm{~ms}, U_{\mathrm{a}}=19 \mathrm{~V}$, $v_{\mathrm{w}}=30 \mathrm{~m} / \mathrm{h}$. In spite of small sagging of weld as a whole, it has structure typical of microplasma welding. Its macrostructure is fine-crystalline, dense, without visible defects. Weld width in the upper part is approximately $2.7 \mathrm{~mm}$, and in the lower part it is $0.7 \mathrm{~mm}$. HAZ size is small enough and it is about $0.27 \mathrm{~mm}$.

Further, penetration (Figure 6, $a$ ) and butt weld (Figure $6, b$ ), made by hybrid method, were studied. In both cases the welding mode was similar: $I_{\text {str }}=30 \mathrm{~A}, I_{\text {rev }}=10 \mathrm{~A}, \tau_{\text {str }}=20 \mathrm{~ms}, \tau_{\mathrm{rev}}=$ $=10 \mathrm{~ms}, U_{\mathrm{a}}=21.5 \mathrm{~V}, v_{\mathrm{w}}=150 \mathrm{~m} / \mathrm{h}, P_{1}=$ $=400 \mathrm{~W}$, focus was on the specimen surface. Difference of penetration depth of sheet of alloy AMg6 from welding of butt joint is due to the gap presence between the edges being welded. Typical defects were undercut on one of weld sides and formation of inner pore of $0.1-0.2 \mathrm{~mm}$ diameter. Elimination of these defects is connected with decrease in arc pressure and plasma gas.

Edge joints of alloy AMg6 $(\delta=1.4 \mathrm{~mm})$ were made by hybrid (Figure 7 ) and laser (Figure 8) methods. The mode of hybrid welding was: $I_{\text {str }}=$ $=12 \mathrm{~A}, I_{\text {rev }}=7 \mathrm{~A}, \tau_{\text {str }}=30 \mathrm{~ms}, \tau_{\text {rev }}=10 \mathrm{~ms}$, $U_{\mathrm{a}}=16 \mathrm{~V}, v_{\mathrm{w}}=168 \mathrm{~m} / \mathrm{h}, Q_{\mathrm{pl.g}}=0.1 \mathrm{l} / \mathrm{min}$, $Q_{\text {sh.g }}=9 \mathrm{l} / \mathrm{min}, Q_{\text {f.l.g }}=3-6 \mathrm{l} / \mathrm{min}, P_{1}=400 \mathrm{~W}$, focus was on the specimen surface. In case of laser welding the weld of about $0.35 \mathrm{~mm}$ depth was formed at speed of $110 \mathrm{~m} / \mathrm{h}$ and maximum power $(400 \mathrm{~W})$.

Size of width of weld and HAZ in hybrid welding at increase of speed decreased and was as follows. For butt joint (Figure 6,b) the width of weld upper part was $1.9 \mathrm{~mm}$, lower part $0.46 \mathrm{~mm}, \mathrm{HAZ}-0.08 \mathrm{~mm}$; for edge joint ( $\mathrm{Fi}^{-}$ gure $7, b$ ) the width of weld upper part was $1.14 \mathrm{~mm}$, lower part - $0.39 \mathrm{~mm}, \mathrm{HAZ}-$ $0.05 \mathrm{~mm}$.

Figure 8 shows the microstructure of metal of welds, produced in cases of microplasma, hybrid and laser welding more in detail. Microstructure of butt and edge joints in hybrid welding was studied separately. Investigation of microstructure in all the produced joints indicates the presence of dendritic structure of cast metal in welds, which becomes somewhat coarser to the periphery. Weld metal has a rather fine-grain structure (grain value is about $50 \mu \mathrm{m}$ ). When evaluating the dispersity of structure of weld metal of test joints, the dendritic parameter is the basic characteristic of structure dispersity alongside with 


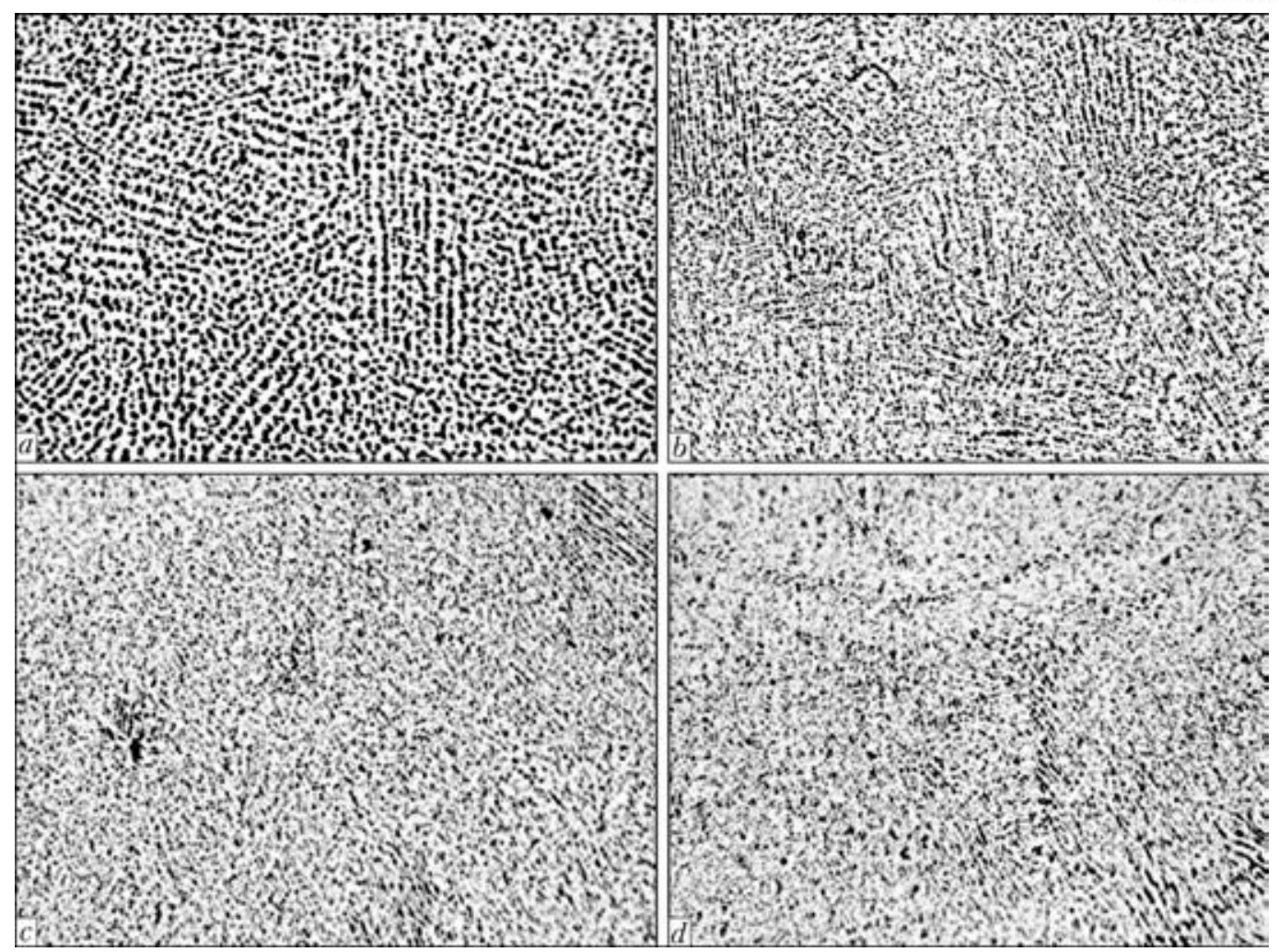

Figure 8. Microstructure $(\times 500)$ of metal of welds obtained by plasma $(a)$, hybrid method in butt $(b)$ and edge $(c)$ joints and by laser $(d)$

a volumetric fraction of structure constituents, thickness of excessive inclusions and their specific surface. It is seen from the comparison of microstructures that the most coarse-dispersed structure is observed in plasma welding, and the most fine-dispersed structure is observed in case of laser welding. Dendritic parameter is about $4 \mu \mathrm{m}$ for plasma welding and almost 3 times decreased for laser welding. In hybrid welding the finerdispersed structure is observed in edge joint. In our opinion, this is due to the increase in welding speed, which became possible by improvement of absorption of laser emission in raised edge.

Investigation of effect of technological parameters of $\mathrm{CO}_{2}$-laser welding on the peculiarities of formation of butt joints of aluminium alloy $\operatorname{AMg} 5(\delta=1.5 \mathrm{~mm})$ was carried out according to scheme in Figure 1. For this, the oxide film from the surface of specimens was removed before welding by using the solution MR-35, developed in NIIKhimProm (Russia). For comparison of obtained results the butt welding and laser beam passing over the metal were used.

In welding of aluminium alloys the pores formation is possible, the source of which is hydrogen, well dissolving in aluminium at melting temperature. Alloys of $\mathrm{Al}-\mathrm{Mg}$ system are characterized by increased susceptibility to porosity in welding, as magnesium increases the hydrogen solubility in aluminium [6]. In accordance with statistics, one of the main defects (about $48 \%$ of rejection) of welded structures of aluminium and magnesium alloys is the gas porosity. Therefore, during this work the porosity of welds was evaluated. As a result of visual-optic investigation the following was found.

In laser welding the «ripple» was observed at all the modes (Figure 9, $a$ ). This is due to the non-stationary processes in weld pool and interruptions in its solidification. Pores, craters in weld and drops of metal, forming during welding, are the defects of welded joints. At the initial moment of welding the numerous pores are observed, caused by metal overheating at increase of speed by technological table. With increase in speed of the process the lack of penetration is observed caused by decrease in power supplied per unit of volume of metal being melted.

To investigate the structure of welds, two macrosections from each specimen were manufactured. For etching the Keller agent was used [7]. In all the cases the scattered pores of small diameters (to $0.2 \mathrm{~mm}$ ) were observed (Figures 10 and 11). For specimens, butt welded by $\mathrm{CO}_{2}$-laser at $420 \mathrm{~m} / \mathrm{h}$ speed, the weld sagging is typical, exceeding $10 \%$ of metal thickness (Figure 10, $a)$. Moreover, undercuts are observed on penetrated sound specimens (Figure 10, $b$ ). At optimum parameters of the process a small porosity is observed (pores of $0.1-0.2 \mathrm{~mm}$ diameter), 

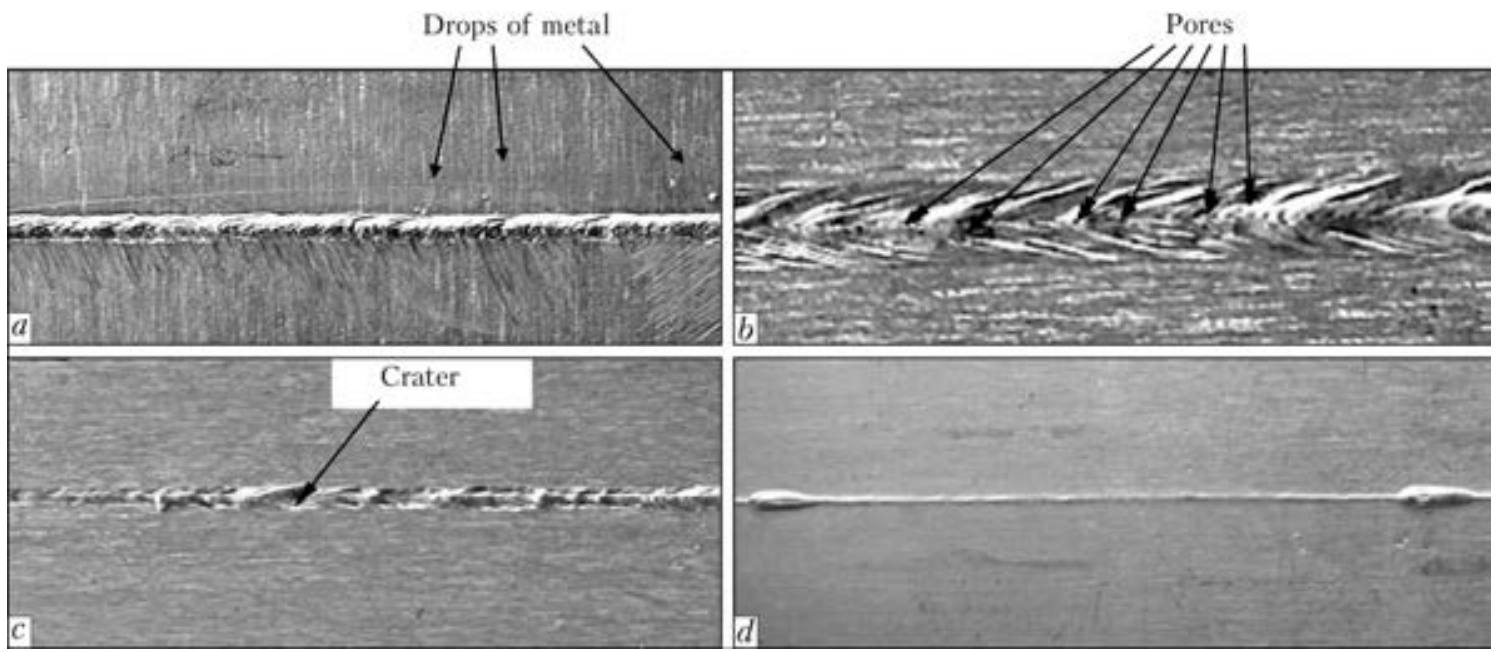

Figure 9. Appearance and typical defects of welded joints $(\times 3): a-c-$ face side; $d-$ reverse side
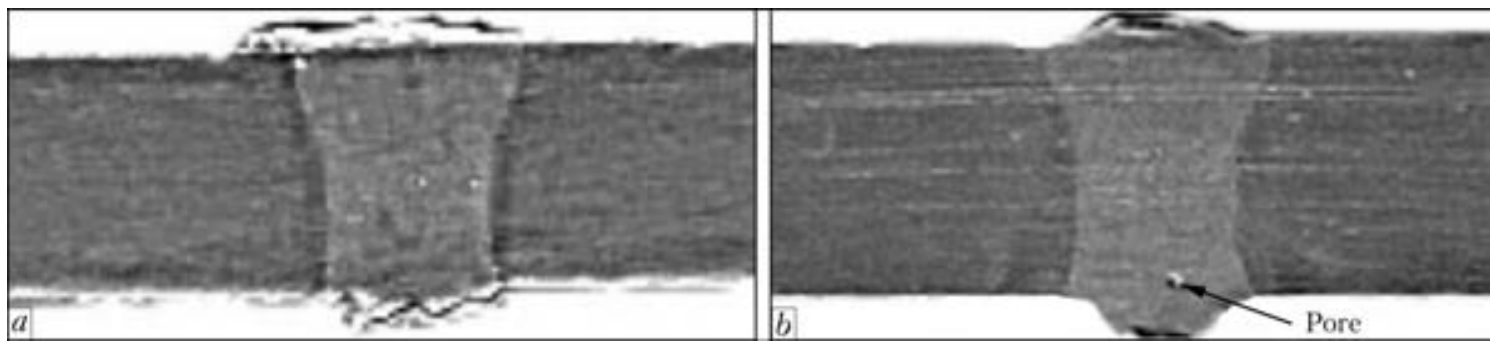

Figure 10. Macrostructure $(\times 20)$ of welded joints of alloy $\operatorname{AMg} 5(\delta=1.5 \mathrm{~mm})$ at $v_{\mathrm{W}}=360 \mathrm{~m} / \mathrm{h}$

which can be considered admissible. It should be noted that a small porosity is also observed in base metal.

It should be noted in conclusion that to produce the quality butt joints of sheet aluminium alloys both in case of laser and also in case of HLMP welding, it is necessary to apply the energy input of about $20 \mathrm{~J} / \mathrm{mm}$ per one millimeter of penetration depth in the range of $100-300 \mathrm{~m} / \mathrm{h}$ speeds. In welding of edge joints this value can decrease to $15 \mathrm{~J} / \mathrm{mm}$ and lower. In this case the use of microplasma constituent in hybrid process allows decreasing the emission power in ratio of about 1:1 due to heat mechanism of increasing the absorption ability of the base metal, thus significantly reducing the equipment cost.

In microplasma welding of aluminium alloys of up to $1.5 \mathrm{~mm}$ thickness the weld sagging in case of complete penetration, tendency to forma-

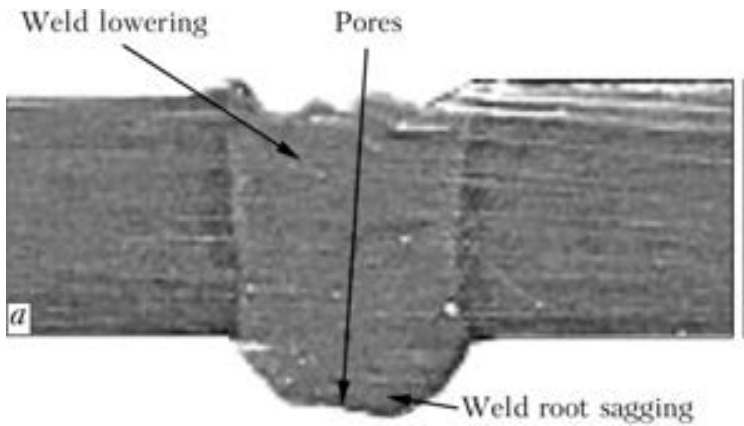

tion of undercuts at current above $30 \mathrm{~A}$, decrease in process stability with increase in speed above $40 \mathrm{~m} / \mathrm{h}$ are observed. The main drawback of laser welding of aluminium alloys by continuous emission is the need in power increase for producing a stable penetration, leading to increase in cost of welding equipment. One of methods of elimination of these drawbacks is the combination of microplasma and laser processes.

The HLMP welding of aluminium alloys of up to $1.5 \mathrm{~mm}$ thickness is characterized by stability of process at speeds above $60 \mathrm{~m} / \mathrm{h}$, decreased width of welds (by 1.5-2 times as compared with microplasma welding), significant reducing of residual deformations, and also by possibility of producing quality joints at comparatively low energy inputs (of about $12-15 \mathrm{~J} / \mathrm{mm}$ for edge joints and about $30 \mathrm{~J} / \mathrm{mm}$ for butt ones), absence of spattering. Typical defects of laser-

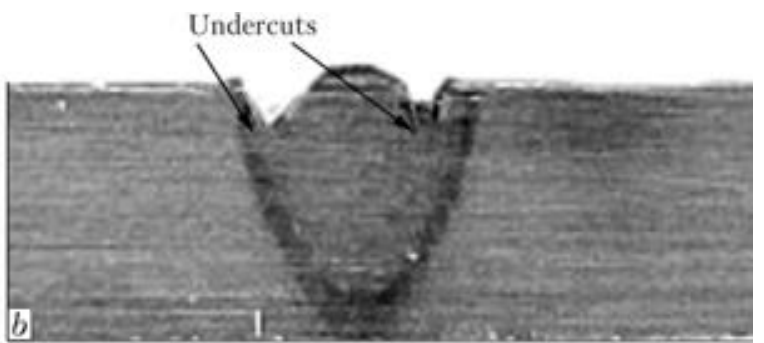

Figure 11. Macrostructure $(\times 20)$ of AMg5 alloy welded joints $(\delta=1.5 \mathrm{~mm})$ at $v_{\mathrm{w}}=420 \mathrm{~m} / \mathrm{h}$ 
microplasma welding of aluminium alloys include sagging of welds, welded without backing, formation of undercuts and inner pores of $0.1-$ $0.2 \mathrm{~mm}$ diameter. The main ways of elimination of these defects can considered the following: feeding of filler metal (for example, in the form of wire); use of steel backings (including those with grooves for lower bead formation); welding along raised edge (by edge welds); overlap welding (requires careful preparation of surfaces); decrease in energy input from microplasma constituent at conservation of general level of energy being input; applying of welding modes with high-frequency modulation of emission power.

The optimum values of parameters of $\mathrm{CO}_{2}$-laser welding are the power of $3.0-3.5 \mathrm{~kW}$ at $180-$ $300 \mathrm{~m} / \mathrm{h}$ speed, i.e. range of energy inputs of $36-70 \mathrm{~J} / \mathrm{mm}$. Reduction in energy input leads to lack of penetration of metal, while its increase - to hot cracks formation. At optimum parameters of the process a small porosity of welded joint is observed (pores of $0.1-0.2 \mathrm{~mm}$ diameter), which is considered as admissible. It should be noted that a small porosity is observed also in base metal.

The detailed study of structures of metal of welds made by plasma, hybrid and laser welding showed that in all the cases the structure is rather equiaxial, dense, without visible defects and has a dendritic nature. The most coarse-dispersed structure is observed in plasma welding, the most fine-dispersed structure - in laser welding. Dendritic parameter is about $4 \mu \mathrm{m}$ for plasma welding and approximately 3 times decreased for laser welding. In hybrid welding the more fine-dispersed structure is observed in edge joint, that is due to increase in welding speed, which became possible by improvement of laser emission absorption in narrow non-through gap formed by a raised edge.

1. Paton, B.E., Gvozdetsky, V.S., Dudko, D.A. et al. (1979) Microplasma welding. Kiev: Naukova Dumka.

2. Paton, B.E., Gvozdetsky, V.S., Krivtsun, I.V. et al. (2002) Hybrid laser-microplasma welding of thin sections of metals. The Paton Welding J., 3, 2-6.

3. Bondarev, A.A., Bondarev, Andr. A. (2001) Laser welding of aluminium alloys (Review). Ibid., 12, 19-25.

4. Krivtsun, I.V., Shelyagin, V.D., Khaskin, V.Yu. et al. (2007) Hybrid laser-plasma welding of aluminium alloys. Ibid., 5, 36-40.

5. Afonin, Yu.V., Golyshev, A.P., Ivanchenko, A.I. et al. (2004) Generation of radiation with quality of TEM00 mode in continuous $\mathrm{CO}_{2}$-laser of $8 \mathrm{~kW}$ power. Kvant. Elektronika, 31(4), 307-310.

6. Rabkin, D.M. (1986) Metallurgy of fusion welding of aluminium and its alloys. Kiev: Naukova Dumka.

7. Kovalenko, V.S. (1981) Metallographic reagents: Refer. Book. 3rd ed. Moscow: Metallurgiya.

Received 07.02.2014 